\title{
Modeling the OH-Initiated Oxidation of Mercury in the Global Atmosphere Without Violating Physical Laws
}

Theodore S. Dibble ${ }^{\mathrm{a} *}$, Hanna L. Tetu ${ }^{\mathrm{a}}$, and Yuge Jiao ${ }^{\mathrm{a}}$, Colin P. Thackray ${ }^{\mathrm{b}}$, Daniel J. Jacob ${ }^{\mathrm{b}, \mathrm{c}}$

a) Department of Chemistry, State University of New York, College of Environmental Science and Forestry, 1 Forestry Drive, Syracuse, NY, 13210

b) Harvard John A. Paulson School of Engineering and Applied Sciences, Harvard University, Cambridge, MA, USA

c) Department of Earth \& Planetary Sciences, Harvard University, Cambridge, MA, USA

\begin{abstract}
In 2005, Calvert and Lindberg wrote that the use of laboratory-derived rate constants for $\mathrm{OH}+$ $\mathrm{Hg}(0)$ "...to determine the extent of $\mathrm{Hg}$ removal by $\mathrm{OH}$ in the troposphere will greatly overestimate the importance of $\mathrm{Hg}$ removal by this reaction." The $\mathrm{HOHg} \bullet$ intermediate formed from $\mathrm{OH}+\mathrm{Hg}$ will mostly fall apart in the atmosphere before it can react. By contrast, in laboratory experiments, Calvert and Lindberg expected $\mathrm{HOHg} \bullet$ to react with radicals (whose concentrations are much higher than in the atmosphere). Yet almost all models of oxidation of $\mathrm{Hg}(0)$ ignore the argument of Calvert and Lindberg. We present a way for modelers to include the $\mathrm{OH}+\mathrm{Hg}$ reaction while accounting quantitatively for the dissociation of $\mathrm{HOHg} \cdot$. We use high levels of quantum chemistry to establish the HO-Hg bond energy as $11.0 \mathrm{kcal} / \mathrm{mole}$, and calculate the equilibrium constant for $\mathrm{OH}+\mathrm{Hg}=\mathrm{HOHg} \cdot$. Using the measured rate constant for association of $\mathrm{OH}$ with $\mathrm{Hg}$, we determine the rate constant for $\mathrm{HOHg} \cdot$ dissociation. Theory is also used to demonstrate that $\mathrm{HOHg} \bullet$ forms stable compounds, $\mathrm{HOHgY}$, with atmospheric radicals $\left(\mathrm{Y}=\mathrm{NO}_{2}\right.$, $\mathrm{HOO} \cdot \mathrm{CH}_{3} \mathrm{OO} \cdot$, and $\mathrm{BrO}$ ). We then present rate constants for use in in modeling $\mathrm{OH}$-initiated oxidation of $\operatorname{Hg}(0)$. We use this mechanism to model the global oxidation of $\operatorname{Hg}(0)$ in the period 2013-2015 using the GEOS-Chem 3D model of atmospheric chemistry. Because of the rapid dissociation of $\mathrm{HOHg} \cdot \mathrm{OH}$ accounts for $<1 \%$ of the global oxidation of $\mathrm{Hg}(0)$ to $\mathrm{Hg}$ (II), while $\mathrm{Br}$ atoms account for $97 \%$.
\end{abstract}

*Corresponding Author: tsdibble@esf.edu 


\section{INTRODUCTION}

The toxicity of mercury motivates research into its environmental chemistry and transport. It has long been realized that the atmosphere enables transport of mercury from emission sites to anywhere in the globe. ${ }^{1}$ Recently, the international community agreed to reduce emissions of mercury in order to reduce harm to humans and the environment. This agreement, the Minimata Convention, calls for modeling of mercury fate and transport in order to guide emissions reductions. $^{2}$

Gaseous elemental mercury ( $\mathrm{Hg}(0)$, aka GEM) dominates mercury emissions to the atmosphere. ${ }^{3}$ GEM is oxidized in the atmosphere to mercuric compounds ( $\mathrm{Hg}(\mathrm{II})$ ), which are soluble in water and, hence, efficiently removed by deposition. ${ }^{1}$ As a result, understanding the mechanism and kinetics of oxidation of $\operatorname{Hg}(0)$ is critically important for predicting when and where mercury enters ecosystems. ${ }^{4,5}$ Yet the scientific community cannot agree on which species initiate the oxidation of GEM! ${ }^{6,7}$ This disagreement hinders the progress of research into the global cycling of mercury.

The hydroxyl radical $(\mathrm{OH})$ is the most important oxidant for most organic and inorganic compounds in the atmosphere, so it is natural to suspect that it might play a major role in GEM oxidation. The reaction of $\mathrm{OH}$ with $\mathrm{Hg}$ is presumed to proceed via:

$$
\mathrm{OH}+\mathrm{Hg}(+\mathrm{M}) \leftrightarrows \mathrm{HOHg} \bullet(+\mathrm{M})
$$

where $\mathrm{M}$ is a third body. The three experimental studies of the kinetics of reaction (1) all agree well with each other; we summarize them here. Sommar et al. used a relative rate technique to obtain $k_{1}=(8.7 \pm 3) \times 10^{-14} \mathrm{~cm}^{3}$ molecule ${ }^{-1} \mathrm{sec}^{-1}$ at $295 \mathrm{~K}$ in 1 atm of air. ${ }^{8}$ Bauer et al reported an upper limit of $1.2 \times 10^{-13} \mathrm{~cm}^{3}$ molecule $\mathrm{sec}^{-1}$ at $298 \mathrm{~K}$ in 400 Torr of air using laser-induced fluorescence (LIF) detection of $\mathrm{OH}$ in the presence of excess $\mathrm{Hg}(0) .{ }^{9}$ Pal and Ariya used relative rate measurements to determine the rate constant as a function of temperature $(283 \mathrm{~K} \leq T \leq 353$ $\mathrm{K})$ in $1 \mathrm{~atm}$ air. ${ }^{10}$ At $295 \mathrm{~K}$, their Arrhenius expression corresponds to a value only $10 \%$ higher than that of Sommar et al.

Subsequently, in 2005, Goodsite et al. ${ }^{11}$ used computational chemistry to study the dissociation of $\mathrm{HOHg} \cdot$. They pointed out that the weak HO-Hg bond (they reported $\mathrm{D}_{0}=9.4$ $\mathrm{kcal} / \mathrm{mole}$ ) would lead to fast dissociation of $\mathrm{HOHg} \bullet$. On account of this fast dissociation, they largely discounted the importance of $\mathrm{OH}$ radical in $\mathrm{Hg}(0)$ oxidation in favor of oxidation by $\mathrm{Br}$ atoms.

Calvert and Lindberg ${ }^{12}$ tried to reconcile the fast dissociation of $\mathrm{HOHg} \bullet$ with the results of the relative rate experiments. They pointed out that the high concentrations of radicals, $\bullet Y$, in those experiments would enable $\mathrm{HOHg} \bullet$ to react with radicals to make stable $\mathrm{Hg}$ (II) compounds via:

$$
\mathrm{HOHg} \bullet+\cdot \mathrm{Y}(+\mathrm{M}) \rightarrow \mathrm{HOHgY}(+\mathrm{M})
$$


in competition with $\mathrm{HOHg} \bullet$ dissociation. They concluded that $\mathrm{OH}$-initiated oxidation of GEM would be much less efficient in the atmosphere than implied by experiments, due to the much lower radical concentrations in the atmosphere. As of this writing, their paper has been cited approximately 200 times, and that of Goodsite et al. has been cited over 250 times, yet almost all models of $\mathrm{Hg}(0)$ oxidation that include $\mathrm{OH}$-initiation assume that the $\mathrm{OH}+\mathrm{Hg}$ reaction is irreversible. This assumption violates detailed balancing.

How do models of the OH-initiated oxidation of GEM reconcile their assumption that reaction (1) is irreversible with the results of Goodsite et al. and Calvert and Lindberg? Some models ignore the issue by using operational definitions of the products rather than specifying their identity. ${ }^{13,14}$ In other instances the assumed irreversibility of reaction (1) is rationalized ${ }^{8,10,15}$ by the rapid occurrence of:

$$
\mathrm{HOHg} \bullet+\mathrm{O}_{2} \rightarrow \mathrm{HgO}+\mathrm{HOO}
$$

However, we know now that reaction (3) cannot occur under atmospheric conditions, because it is endothermic by $\sim 60 \mathrm{kcal} / \mathrm{mole}^{16-20}$ This endothermicity largely arises from the very low bond energy of $\mathrm{HgO}(\sim 4 \mathrm{kcal} / \mathrm{mole})$. Furthermore, as a result of its weak bonding, the $\mathrm{HgO}$ molecule will fall apart extremely rapidly:

$$
\mathrm{HgO} \rightarrow \mathrm{Hg}+\mathrm{O}
$$

As a result of reaction (4), the occurrence of reaction (1) followed by reaction (3) cannot account for the loss of $\operatorname{Hg}(0)$ observed in the presence of $\mathrm{OH}$ without violating the law of mass conservation. While the last several years have seen extensive studies of the kinetics and mechanism of Br-initiated oxidation of $\mathrm{Hg}(0),{ }^{18,21-28}$ similar work has not been carried out for OH-initiated oxidation.

The importance of $\mathrm{OH}$ in initiating $\mathrm{Hg}(0)$ oxidation depends, in large part, on the rate of $\mathrm{HOHg} \cdot$ dissociation and the rate of oxidation of $\mathrm{HOHg} \bullet$ to $\mathrm{Hg}(\mathrm{II})$ compounds. The rate of $\mathrm{HOHg} \cdot$ dissociation has not been determined experimentally, and depends sensitively on the $\mathrm{HO}-\mathrm{Hg}$ bond energy. We start by using quantum chemistry to determine the HO-Hg bond dissociation energy with high precision. We also show that the $\mathrm{HHgO} \bullet$ isomer of $\mathrm{HOHg} \bullet$ will not form from $\mathrm{OH}+\mathrm{Hg}$. Using standard methods of statistical mechanics we then obtain the equilibrium constant, $K_{1}(T)$, for $\mathrm{HO}-\mathrm{Hg}$ formation in reaction (1). Together with the experimental measurements of $k_{1}(T)$, this enables determination of the rate constant, $k_{-1}(T)$, for $\mathrm{HOHg} \bullet$ dissociation. Following this, we use quantum chemistry to demonstrate that $\mathrm{HOHg}$, like $\mathrm{BrHg} \cdot{ }^{24,29}$ forms thermally stable molecules in addition reactions with $\mathrm{NO}_{2}, \mathrm{HOO}, \mathrm{CH}_{3} \mathrm{OO}$, and $\mathrm{BrO}$ :

$$
\begin{aligned}
& \mathrm{HOHg} \bullet+\mathrm{NO}_{2} \rightarrow \mathrm{HOHgONO} \text { (and isomers) } \\
& \mathrm{HOHg} \bullet+\mathrm{HOO} \bullet \rightarrow \mathrm{HOHgOOH} \\
& \mathrm{HOHg} \bullet+\mathrm{CH}_{3} \mathrm{OO} \bullet \rightarrow \mathrm{HOHgOOCH}_{3} \\
& \mathrm{HOHg} \bullet+\mathrm{BrO} \bullet \rightarrow \mathrm{HOHgOBr}
\end{aligned}
$$


Also like $\mathrm{BrHg} \bullet, \mathrm{HOHg} \bullet$ binds rather weakly to $\mathrm{O}_{2}$ and $\mathrm{NO}$ :

$$
\begin{aligned}
& \mathrm{HOHg} \bullet+\mathrm{O}_{2} \leftrightarrows \mathrm{HOHgOO} \bullet \\
& \mathrm{HOHg} \bullet+\mathrm{NO} \leftrightarrows \mathrm{HOHgNO}
\end{aligned}
$$

such that dissociation of $\mathrm{HOHgOO} \bullet$ and $\mathrm{HOHgNO}$ occurs more rapidly than they could undergo other reactions. Next, we present arguments that $\mathrm{HOHg} \bullet$ will not abstract hydrogen atoms from volatile organic compounds (VOCs) and will not add efficiently to alkenes. We then use the parallels between the HOHg-Y and BrHg-Y bond energies to suggest a set of rate constants for use in modeling the $\mathrm{OH}$-initiated oxidation of $\mathrm{Hg}(0)$. Finally, we present results of modeling of the effect of $\mathrm{OH}$-initiated oxidation of $\mathrm{Hg}(0)$ on global mercury concentrations.

\section{METHODS}

Calculations on HOHg-Y compounds used Gaussian $09^{30}$ and Gaussian $16 .{ }^{31}$ Spin-unrestricted methods were used for open-shell molecules except as noted. The standard Dunning's (aug-)cc$\mathrm{pVXZ}^{32}(X=\mathrm{D}, \mathrm{T}, \mathrm{Q}$, or 5) basis sets were used for $\mathrm{O}$ and $\mathrm{H}$. To account for scalar relativistic effects, we used the Stuttgart/Cologne scalar pseudopotentials for the 60 innermost electrons of $\mathrm{Hg}$ (ECPMDF60). ${ }^{33-35}$ The corresponding (aug)-cc-pVXZ basis sets of Peterson and co-workers for electrons outside this ECP. ${ }^{33,35,36}$ Hereafter, we refer to this combination of pseudopotentials and basis sets as VXZ or AVXZ (when augmented with diffuse functions). Where not otherwise specified, post-Hartree-Fock methods correlated only the $5 \mathrm{~d}$ and $6 \mathrm{~s}$ electrons of $\mathrm{Hg}$, the $4 \mathrm{~s}$ and $4 p$ electrons of $\mathrm{Br}$, and the valence electrons of $\mathrm{H}, \mathrm{C}, \mathrm{N}$, and $\mathrm{O}$.

Calculations to determine $\mathrm{HOHg}-\mathrm{Y}$ bond energies and the relative energy of $\mathrm{HOHg} \bullet$ and its $\mathrm{HHgO} \bullet$ isomer were carried out using geometries and unscaled harmonic vibrational frequencies (and zero-point energies) computed at PBE0/AVTZ. These calculations used a pruned grid of 99 radial shells with 590 angular points per shell. This level of theory has proven to do a good job for structure and vibrational frequencies of the analogous BrHgY species. ${ }^{24,29}$ Energies were recalculated at $\operatorname{CCSD}(\mathrm{T}) / \mathrm{AVTZ}$.

The HO-Hg bond energy was determined by a composite method similar to the HEAT345-(Q) protocol. ${ }^{37,38}$ Coupled-cluster calculations used CFOUR Beta v2. $0^{39}$, except that UHF-CCSDT(Q) calculations were done by MRCC codes. $^{40}$ RASSI/CASPT2 calculations were carried using Molcas 8.0. ${ }^{41}$ First, the geometries of $\mathrm{OH}$ and $\mathrm{HOHg} \bullet$ were optimized at $\mathrm{CCSD}(\mathrm{T})$ with AVTZ and AVQZ basis sets using analytical gradients. ${ }^{42}$ Harmonic vibrational frequencies were calculated at $\operatorname{CSSD}(\mathrm{T}) / \mathrm{AVTZ}$. Geometries were reoptimized using the analogous valence basis sets designed for correlating all electrons not included in the ECP. ${ }^{36,43}$ We denote this combination of basis sets and pseudopotentials as AwCVTZ. We determined core-valence effect on geometry, $\triangle \mathrm{CV}$, from the difference between geometric parameters computed at $\operatorname{CCSD}(\mathrm{T}) / \mathrm{AVTZ}$ versus CCSD(T,Full)/AwCVTZ. 
Absolute energies were refined at the $\operatorname{CCSD}(\mathrm{T}) / \mathrm{AVQZ}+\Delta \mathrm{CV}$ geometries. $\operatorname{CCSD}(\mathrm{T})$ energies with all electrons correlated were extrapolated to the complete basis set (CBS) limit using $\operatorname{CCSD}(\mathrm{T}) / \mathrm{AwCV} X Z$ energies for $X=3(\mathrm{~T}), 4(\mathrm{Q})$, and 5 by fitting to the formula: ${ }^{44,45}$

$$
E(n)=E_{C B S}+B e^{-(n-1)}+C e^{-(n-1)^{2}}
$$

These CCSD(T,Full)/CBS energies were used to obtain an initial value of the zero-point energyexclusive bond energy at $0 \mathrm{~K}\left(\mathrm{D}_{\mathrm{e}, \mathrm{CBS}}\right)$. As described below, correction terms to this value of $\mathrm{D}_{\mathrm{e}}$ were added to account for the full triples excitations, a perturbative estimate of the quadruple excitations, and spin orbit coupling.

The effect, $\Delta \mathrm{T}$, of the difference between the perturbative estimate of the triples excitation and its exact expresssion ${ }^{46,47}$ was determined by taking the difference between $\mathrm{D}_{\mathrm{e}}$ computed at CCSDT/VTZ and CCSD(T)/VTZ:

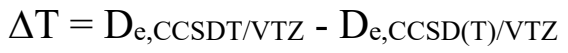

The corrections for the noniterative quadruple excitation ${ }^{48,49}(\Delta(\mathrm{Q}))$ were applied by comparing CCSDT(Q)/VDZ energies and CCSDT/VDZ energies as:

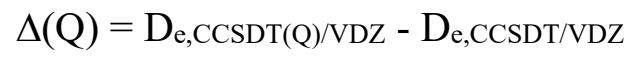

The correction for spin-orbit coupling ( $\triangle \mathrm{SOC})$ was computed using the restricted active space state interaction (RASSI) method ${ }^{50,51}$ with complete active space second-order perturbation theory (CASPT2) $)^{52,53}$ using the atomic mean field integral (AMFI) ${ }^{54}$ algorithm. The DK2 Hamiltonian was used in conjunction with relativistic RCC-ANO basis sets. ${ }^{55,56}$ The active space includes the $6 \mathrm{~s}$ and $6 \mathrm{p}$ orbitals for $\mathrm{Hg}$ and the $2 \mathrm{~s}$ and $2 \mathrm{p}$ orbitals for $\mathrm{O}$. This approach yields a zero-field splitting for $\mathrm{OH}$ radical of $148 \mathrm{~cm}^{-1}$, which agrees well with the experimental value of $139.2 \mathrm{~cm}^{-1} .{ }^{57}$ Expanding the active space from $(5 \mathrm{e}, 6 \mathrm{o})$ to $(7 \mathrm{e}, 7 \mathrm{o})$ lowered this zero-field splitting

by only $1.5 \mathrm{~cm}^{-1}$, suggesting that increasing the size of the active space would not significantly improve the accuracy of the calculation. Subtracting the reaction energy of the lowest spin-free (SF) state from that of the lowest spin-orbit (SO) state yields $\triangle \mathrm{SOC}$ :

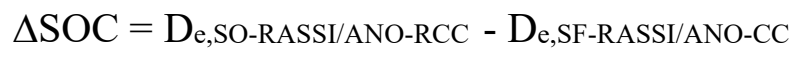

Zero-point energies (ZPEs) of $\mathrm{OH}$ and $\mathrm{HOHg} \bullet$ were computed at $\mathrm{CCSD}(\mathrm{T}) / \mathrm{AVTZ}$. The final value of the bond energy, $D_{0}$, was computed as:

$$
\mathrm{D}_{0}=\mathrm{D}_{\mathrm{e}, \mathrm{CBS}}+\Delta \mathrm{T}+\Delta(\mathrm{Q})+\Delta \mathrm{SOC}+\Delta \mathrm{ZPE}
$$

\section{Results and Discussion}

$\mathbf{O H}+\mathbf{H g}=\mathbf{H O H g} \cdot$. Figure 1 displays the geometry of $\mathrm{HOHg} \bullet$ and Table 1 compares the present results with previous theoretical results. The structure is rather sensitive to the method and basis set employed. Note that the CCSD(T)/AVQZ structure of Saiz-Lopez et al. ${ }^{26}$ is very close to that reported here (Hg-O distance shorter by $0.007 \AA$ ), but rather different from the geometry they 
reported using MRCISD+Q. The $\mathrm{H}-\mathrm{O}$ bond distance is $0.0037 \AA$ smaller in $\mathrm{HOHg}$ • than in the $\mathrm{OH}$ radical at the $\mathrm{CCSD}(\mathrm{T}) / \mathrm{AVQZ}+\Delta \mathrm{CV}$ level of theory. Table 2 lists the harmonic vibrational frequencies and band intensities of $\mathrm{HOHg} \cdot$, in which the frequency of the $\mathrm{O}-\mathrm{H}$ stretch mode is only $31 \mathrm{~cm}^{-1}$ larger than in the $\mathrm{OH}$ radical. These small differences in structure and vibrational frequency between $\mathrm{OH}$ radical and the $\mathrm{OH}$ group of $\mathrm{HOHg} \bullet$ do not reflect the large change in electronic structure upon addition of $\mathrm{Hg}$ to $\mathrm{OH}$ : both the Mulliken and Hirshfeld population analyses assign over half the spin density in $\mathrm{HOHg} \bullet$ to the mercury atom.

Table 1. Structural parameters of $\mathrm{HOHg} \bullet\left({ }^{2} \mathrm{~A}^{\prime}\right)$ reported in several studies (distances, $\mathrm{R}$, in Ångstroms and angle, A, in degrees).

\begin{tabular}{|c|c|c|c|c|}
\hline Method & $\mathrm{R}(\mathrm{H}-\mathrm{O})$ & $\mathrm{R}(\mathrm{O}-\mathrm{Hg})$ & $\mathrm{A}(\mathrm{HOHg})$ & Ref. \\
\hline B3LYP/CEP-121G & 0.99 & 2.25 & 106.8 & 11 \\
\hline B3LYP/AVTZ & 0.9690 & 2.2079 & 103.6 & 58 \\
\hline B3LYP/ZORA-GI/NESC ${ }^{b}$ & -- & 2.181 & -- & 20 \\
\hline M06-2X/AVTZ & 0.964 & 2.100 & 106.2 & 59 \\
\hline MRCISD+Q/aug-cc-pVQZ & 0.9433 & 2.1342 & 106.9 & 26 \\
\hline $\operatorname{CCSD}(\mathrm{T}, \mathrm{Full}) / \mathrm{AwCVTZ}+\Delta \mathrm{CV}$ & 0.9662 & 2.1031 & 103.88 & this work \\
\hline
\end{tabular}

a) using ECP60MWB

b) using a triple- $\zeta$ basis set

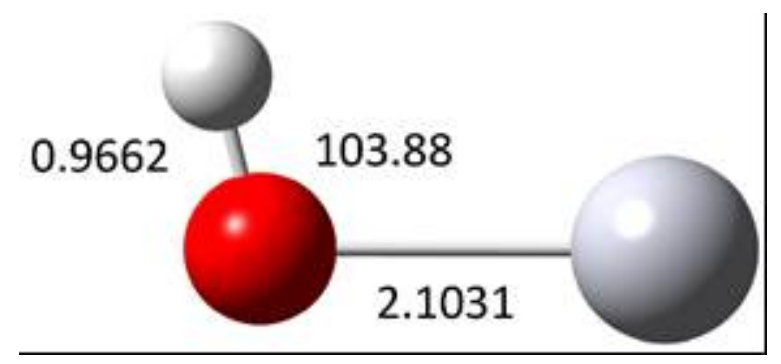

Figure 1. Geometry (bond distances in $\AA$ and bond angles in degrees) of $\mathrm{HOHg} \cdot\left({ }^{2} A^{\prime}\right)$ at $\operatorname{CCSD}(\mathrm{T}, \mathrm{Full}) / \mathrm{AwCVTZ}+\Delta \mathrm{CV}$.

Table 2. Vibrational mode descriptions, harmonic frequencies $\left(v, \mathrm{~cm}^{-1}\right)$, and integrated absorption intensities $(\mathrm{S}, \mathrm{km} / \mathrm{mol})$ for $\mathrm{HOHg} \bullet$ at $\mathrm{CCSD}(\mathrm{T}) / \mathrm{AVTZ}$.

\begin{tabular}{ccc}
\hline mode & $\boldsymbol{v}$ & $\boldsymbol{S}$ \\
\hline HgO stretch & 401.4 & 10.2 \\
HOHg bend & 824.0 & 45.0 \\
OH stretch & 3749 & 42.0 \\
\hline
\end{tabular}


Table 3 lists the various contributions to the HO-Hg bond energy $\left(\mathrm{D}_{0}\right)$. Note that the extrapolation of $\operatorname{CCSD}(\mathrm{T}, \mathrm{Full})$ energies from AwCV5Z to the CBS limit changes the bond energy by only $0.18 \mathrm{kcal} / \mathrm{mole}$. The other correction terms are modest, which encourages us to believe that the final result is very accurate. The $T_{1}$ diagnostic $^{60}$ for $\mathrm{HOHg} \bullet$ is only 0.020 , which is consistent with the modest effects we observe when extending the coupled cluster calculations past the perturbative estimate of the triples correction. As can be seen from Table 3, the sum of the $\Delta \mathrm{T}+\Delta(\mathrm{Q})+\Delta \mathrm{SOC}$ terms is quite small.

Table 3. Contributions to the HO-Hg bond energy ( $\mathrm{kcal} / \mathrm{mol})$.

\begin{tabular}{lc} 
Term & Value \\
\hline $\operatorname{CCSD}(\mathrm{T}$, Full)/CBS & 12.45 \\
$\Delta \mathrm{T}$ & 0.14 \\
$\Delta(\mathrm{Q})$ & 0.32 \\
$\Delta \mathrm{SO}$ & -0.10 \\
$\Delta \mathrm{ZPE}$ (harmonic) & -1.80 \\
Total & 11.02 \\
\hline
\end{tabular}

The HEAT345-(Q) method, which is similar to the approach used here, has an uncertainty of about $0.2 \mathrm{kcal} / \mathrm{mol}$ for bond energies of diatomic molecules in the first two rows of the periodic table. ${ }^{37,38,61}$ As discussed elsewhere, there are no benchmarks for HEAT345-(Q) for mercury compounds. ${ }^{62}$ HEAT345-(Q) includes a correction for the diagonal Born-Oppenheimer approximation. Because the bond being formed in reaction (1) is between two non-hydrogen atoms, we expect this correction to be negligible here. We estimate our value of $\mathrm{D}_{0}$ to have an uncertainty ( 2 s.d.) of about $0.4 \mathrm{kcal} / \mathrm{mole}$; this assessment relies on the small size of the corrections to the CCSD(T,Full)/CBS energies seen in Table 3 and the high accuracy expected of the $\operatorname{CCSD}(\mathrm{T}$, Full)/AwCVTZ geometry and $\operatorname{CCSD}(\mathrm{T}) / \mathrm{AVTZ}$ harmonic frequencies.

Goodsite et al. ${ }^{11}$ and Ezarfi et al..$^{58}$ obtained somewhat lower values of $\mathrm{D}_{0}$ that we did $(9.0$ and $9.5 \mathrm{kcal} / \mathrm{mole}$, respectively). They both used a low level of theory (B3LYP), so the discrepancy between their values and ours is understandable. Cremer et al. used explicitly relativistic calculations with a basis set that was triple-zeta quality; they computed $\operatorname{CCSD}(\mathrm{T})$ energies at a B3LYP geometry. ${ }^{20}$ Their bond enthalpy of $12.4 \mathrm{kcal} / \mathrm{mole}$ at $298 \mathrm{~K}$ corresponds to $\mathrm{D}_{0}$ of $11.4 \mathrm{kcal} / \mathrm{mole}$, which agrees very well with our result. Tossell ${ }^{63}$ reported $\mathrm{D}_{0}$ of only 5.5 $\mathrm{kcal} / \mathrm{mole}$ ay $\mathrm{CCSD}(\mathrm{T}) / / \mathrm{CCD} / \mathrm{SBK}$. Guzman and Bozzelli ${ }^{59}$ reported a bond enthalpy of 14.1 $\mathrm{kcal} / \mathrm{mole}$ at $298 \mathrm{~K}$, corresponding to $\mathrm{D}_{0}$ of $13.1 \mathrm{kcal} / \mathrm{mole}$. Although their bond enthalpy was based on CCSD(T)/CBS energies, it relied on experimental values of the enthalpies of formation of mercury halides-values that possess uncertainties of at least $2 \mathrm{kcal} / \mathrm{mole} .{ }^{64}$ Note that one theoretical study reported the unphysical result that $\mathrm{HOHg} \bullet$ was unstable by $21 \mathrm{kcal} / \mathrm{mole}$ with respect to $\mathrm{OH}+\mathrm{Hg} .{ }^{65}$

Recall that the product of $\mathrm{OH}+\mathrm{Hg}$ has not been determined experimentally. Conceivably, this reaction could produce $\mathrm{HHgO} \cdot$. Because $\mathrm{HHgO} \bullet$ is an $\mathrm{Hg}(\mathrm{II})$ compound, formation of 
$\mathrm{HHgO} \bullet$ from $\mathrm{OH}+\mathrm{Hg}$ would tend to invalidate the arguments of Calvert and Lindberg regarding the efficiency of $\mathrm{OH}$-initiated oxidation of $\mathrm{Hg}(0)$. Note that, based on literature thermodynamics, ${ }^{66,21}$ one can estimate that $\mathrm{BrHgO} \cdot$ and $\mathrm{ClHgO} \bullet$ are more stable than the corresponding $\mathrm{BrO}-\mathrm{Hg}$ and $\mathrm{ClO}-\mathrm{Hg}$ complexes by almost $20 \mathrm{kcal} / \mathrm{mole}$. So we were somewhat surprised to find that $\mathrm{HHgO} \bullet$ lies 37.7 (36.0) $\mathrm{kcal} / \mathrm{mol}$ above $\mathrm{HOHg} \bullet$ at the $\mathrm{CCSD}(\mathrm{T}) / / \mathrm{PBE} 0 / \mathrm{AVTZ}$ (PBE0/AVTZ) level of theory. Given these results, we can conclude that $\mathrm{HHgO} \bullet$ cannot be formed from $\mathrm{OH}+\mathrm{Hg}$.

Using the value of $\mathrm{D}_{0}$ obtained here, together with literature data on $\mathrm{Hg}$ and $\mathrm{OH}$ (listed in the Supporting Information), we computed the equilibrium constant, $K_{\mathrm{c}}(T)$, for reaction (1) at several temperatures over the range $200-320 \mathrm{~K}$. These values can be fit with less than $2 \%$ error by the expression:

$$
K_{\mathrm{c}}=2.74 \times 10^{-24} \mathrm{e}^{+5770 \mathrm{~T}} \mathrm{~cm}^{3} \text { molecule }{ }^{-1}
$$

We now use $K_{\mathrm{c}}(\mathrm{T})$ and $k_{1}(T)$ to determine the rate constant, $k_{-1}(T)$, for dissociation of $\mathrm{HOHg}$. Pal and Ariya ${ }^{10}$ reported the bimolecular rate constant, $k_{1},(T, 1 \mathrm{~atm})$, for $\mathrm{HOHg} \bullet$ formation as $3.55 \times 10^{-14} \mathrm{e}^{+294 / \mathrm{T}} \mathrm{cm}^{3}$ molecule ${ }^{-1} \mathrm{sec}^{-1}$ at 1 atm of pressure. The rate constant will depend on the pressure. Given that the analogous reactions forming $\mathrm{ClHg} \bullet$ and $\mathrm{BrHg} \bullet$ appear to be in the lowpressure limit at pressures up to $600 \mathrm{Torr},{ }^{67,68}$ and given that the $\mathrm{HO}-\mathrm{Hg}$ bond is significantly weaker than the bonds in $\mathrm{ClHg}$ and $\mathrm{BrHg},{ }^{20}$ we assume that reaction (1) is also in the lowpressure limit. This implies that $k_{1}(T, 1 \mathrm{~atm})=k_{1,0}(T)[\mathrm{M}]_{1 \mathrm{~atm}}$, where $k_{1,0}(T)$ is the rate constant in the low-pressure limit and $[\mathrm{M}]_{1 \mathrm{~atm}}$ is the total number density of gas phase species at one atmosphere total pressure at the corresponding temperature. With this assumption, we can express the rate of reaction (1) as:

$$
\text { Rate }=k_{1,0}(T)[\mathrm{OH}][\mathrm{Hg}][\mathrm{M}]
$$

We find $k 1,0(T)$, the termolecular association rate constant, to be:

$$
k_{1}(T)=3.34 \times 10^{-33} \mathrm{e}^{-43 / \mathrm{T}} \mathrm{cm}^{6} \text { molecule }{ }^{-2} \mathrm{sec}^{-1}
$$

with error of less than $1.5 \%$ due to the fitting expression. The resulting bimolecular rate constant for dissociation of $\mathrm{HOHg} \bullet$ is fit to within $4 \%$ by the expression:

$$
k_{-1,0}(T)=1.22 \times 10^{-9} \mathrm{e}^{+5720 / \mathrm{T}} \mathrm{cm}^{3} \text { molecule } \mathrm{e}^{-1} \mathrm{sec}^{-1}
$$

where the rate of dissociation equals $k_{-1,0}(T)[\mathrm{HOHg} \cdot][\mathrm{M}]$. At $298 \mathrm{~K}$ and $1 \mathrm{~atm}, k_{-1,0}$ equals 140 $\mathrm{sec}^{-1}$, corresponding to a lifetime of only $7 \mathrm{~ms}$. This lifetime is significantly longer than the 0.3 ms computed by Goodsite et al., ${ }^{11}$ on account of our finding a stronger bond energy.

Bimolecular Reactions of $\mathbf{H O H g}$ • Figure 2 depicts the structures of the stable $\mathrm{Hg}(\mathrm{II})$ species that can be formed in reactions of $\mathrm{HOHg} \bullet$ with various atmospherically abundant radicals $(\cdot \mathrm{Y})$. $\mathrm{HOHg}-\mathrm{Y}$ distances are very similar to those computed for $\mathrm{BrHg}-\mathrm{Y}$ at the same level of theory. ${ }^{24}$ Paralleling our results for $\mathrm{BrHg} \bullet+\mathrm{NO}_{2}$, interaction of $\mathrm{HOHg} \bullet$ with $\mathrm{NO}_{2}$ yields three isomers/conformers: $\mathrm{HOHgNO}_{2}$, anti-HOHgONO, and syn-HOHgONO. Figure 3 depicts the potential energy profile for the $\mathrm{HOHg} \cdot+\mathrm{NO}_{2}$ system, including transition states for 
isomerization of $\mathrm{HOHgNO}_{2}$ to anti-HOHgONO to syn- $\mathrm{HOHgONO}$. Note that the $\mathrm{HOHgO} \bullet+$ $\mathrm{NO}$ (not shown in Figure 3) lies $7 \mathrm{kcal} / \mathrm{mole}$ above $\mathrm{HOHg} \bullet+\mathrm{NO}_{2}$ at $\mathrm{CCSD}(\mathrm{T}) / / \mathrm{PBE} 0 / \mathrm{AVTZ}$, so $\mathrm{HOHgO} \bullet+\mathrm{NO}$ will not form from $\mathrm{HOHg}+\mathrm{NO}_{2}$.
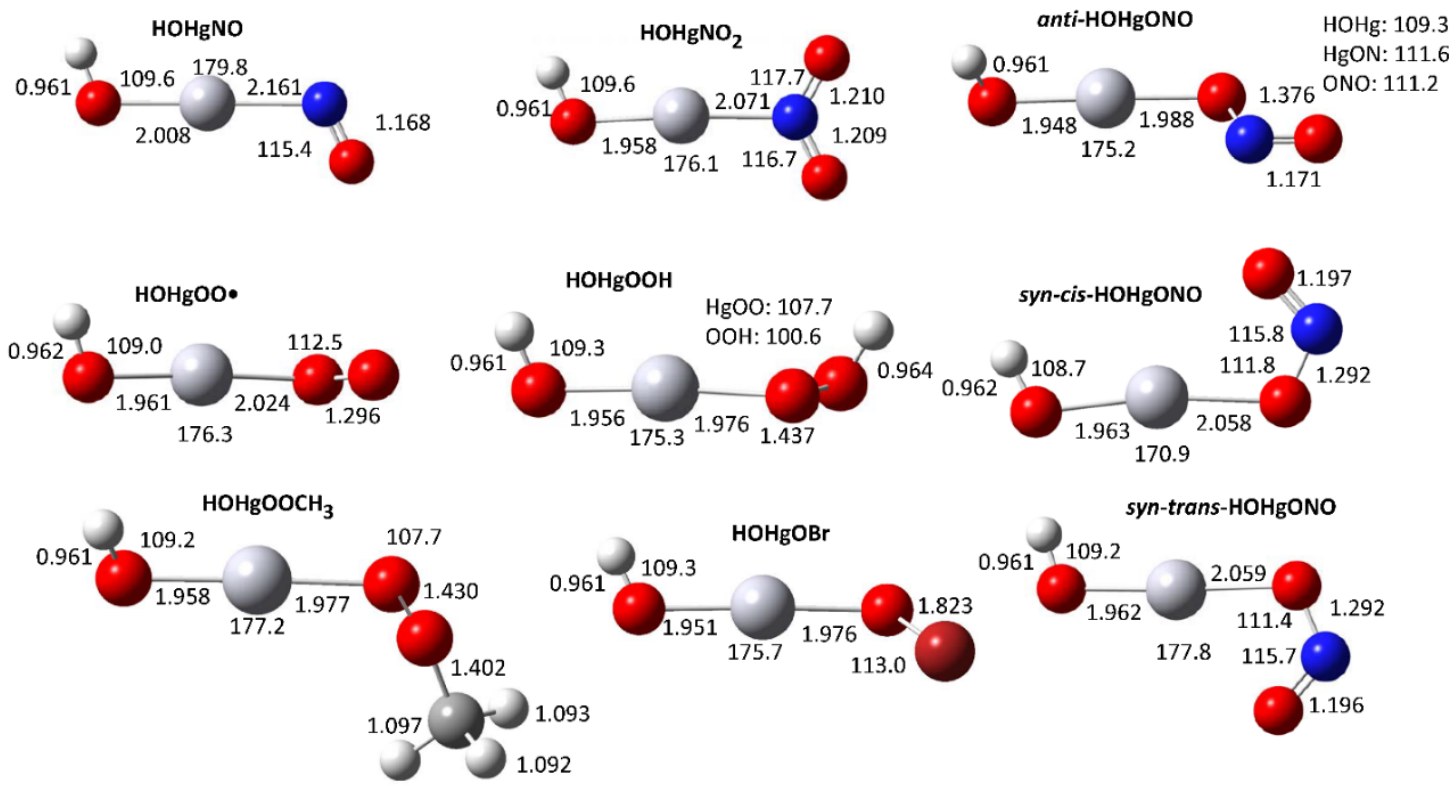

Figure 2. Structures of $\mathrm{HOHgY}$ compounds. Bond lengths (in $\AA$ ) and angles (in degrees) at PBE0/AVTZ.

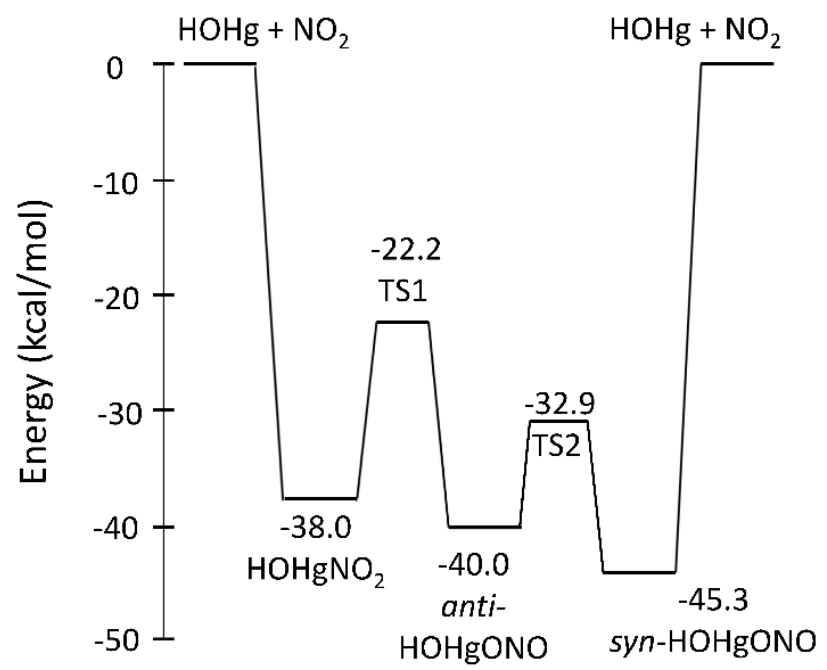

Figure 3: Potential Energy Profile for $\mathrm{HOHg} \bullet+\mathrm{NO}_{2}$ at $\mathrm{CCSD}(\mathrm{T}) / / \mathrm{PBE} 0 / \mathrm{AVTZ}$. The two conformers of syn-HOHgONO are treated as one species here. 
At $298 \mathrm{~K}, 99.98 \%$ of the products of $\mathrm{HOHg} \bullet+\mathrm{NO}_{2}$ will exist as syn- $\mathrm{HOHgONO}$. RRKM/Master Equation calculations in MultiWell ${ }^{69-71}$ and MESMER ${ }^{72}$ indicate that at conditions typical of the tropopause (220 K and $0.1 \mathrm{~atm})$, more than $90 \%$ of $\mathrm{HOHgNO}_{2}$ will promptly ( $\sim 20 \mathrm{ps})$ isomerize to the $\mathrm{HOHgONO}$ conformers, and the anti conformer is transformed to the syn conformer in less than $1 \mu \mathrm{s}$. However, under these conditions, the lifetime for transforming the small remaining fraction of thermalized $\mathrm{HOHgNO}_{2}$ to syn- $\mathrm{HOHgONO}$ is about $1000 \mathrm{sec}$. By contrast, at $1 \mathrm{~atm}$ and $298 \mathrm{~K}$, the system only takes about 1 second to reach equilibrium. For modeling purposes, it seems reasonable to treat syn- $\mathrm{HOHgONO}$ as the sole product of addition of $\mathrm{NO}_{2}$ to $\mathrm{HOHg} \bullet$.

$\mathrm{HOHg}-\mathrm{Y}$ bond energies $\left(\mathrm{D}_{0}\right)$ are listed in Table 4. Note that Guzman and Bozzelli ${ }^{59}$ obtained $56.2 \mathrm{kcal} / \mathrm{mole}$ (at $298 \mathrm{~K}$ ) for the $\mathrm{HOHg}-\mathrm{OBr}$ bond enthalpy, which is in good agreement with our value of $\mathrm{D}_{0}=56.7 \mathrm{kcal} / \mathrm{mole}$. Figure 4 shows that values of $\mathrm{D}_{0}$ for each $\mathrm{HOHg}-\mathrm{Y}$ compound nearly match those for the corresponding BrHg-Y. ${ }^{21}$ Regression analysis shows them to correlate as:

$$
\mathrm{D}_{0}(\mathrm{HOHg}-\mathrm{Y})=1.008 \times \mathrm{D}_{0}(\mathrm{HOHg}-\mathrm{Y})+1.2 \mathrm{kcal} / \mathrm{mole}
$$

with $\mathrm{R}^{2}=0.996$. Note two methodological differences between these two studies: structures were obtained with $\mathrm{PBEO}$ for $\mathrm{HOHgY}$ and $\mathrm{B} 3 \mathrm{LYP}$ for $\mathrm{BrHgY}$; also, the BrHg-Y calculations correlated more orbitals than is proper for the AVTZ basis set. For higher level studies of the structures and energetics of $\mathrm{BrHgY}$ compounds, see references 24 and ${ }^{62}$.

\begin{tabular}{|l|c|c|}
\hline $\mathbf{Y}$ & PBE0 & CCSD(T)//PBE0 \\
\hline -OBr & 51.9 & 56.7 \\
\hline -ONO (syn-cis) & 39.0 & 45.3 \\
\hline -ONO (syn-trans) & 38.8 & 45.2 \\
\hline -ONO (anti) & 33.0 & 40.0 \\
\hline - $\mathrm{NO}_{2}$ & 35.3 & 38.0 \\
\hline$-\mathrm{OOH}$ & 38.6 & 44.1 \\
\hline -OOCH & 38.1 & 44.1 \\
\hline -NO & 11.2 & 11.0 \\
\hline$-\mathrm{O}_{2}$ & 8.6 & 9.3 \\
\hline
\end{tabular}

Table 4: HOHg-Y bond energies (kcal/mole at $0 \quad \mathrm{~K})$ at PBE0/AVTZ and CCSD(T)//PBE0/AVTZ.

Although we previously discussed the possibility that $\mathrm{BrHg} \bullet$ would react with organic peroxy radicals (ROO•) to form $\mathrm{BrHgOOR},{ }^{22}$ no studies of this reaction have been published. Here we find that the $\mathrm{HOHg}-\mathrm{OOCH}_{3}$ bond energy to be the same as that for $\mathrm{HOHg}-\mathrm{OOH}$. This tends to support our speculations on the stability of $\mathrm{BrHgOOR}$. 


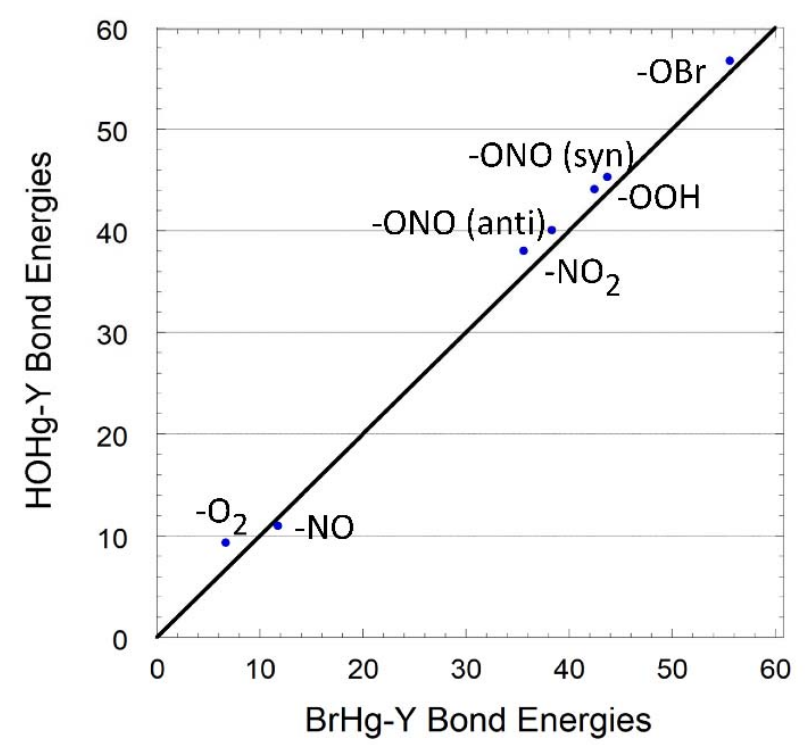

Figure 4: $\mathrm{HOHg}-\mathrm{Y}$ bond energies $(\mathrm{kcal} / \mathrm{mole}$ at $\mathrm{CCSD}(\mathrm{T}) / \mathrm{PBE} 0 / \mathrm{AVTZ})$ from this work vs. $\mathrm{BrHg}-\mathrm{Y}$ bond energies $(\mathrm{CCSD}(\mathrm{T}) / / \mathrm{B} 3 \mathrm{LYP} / \mathrm{AVTZ})$ from Ref 21. The diagonal line corresponds to equal bond energies in the two classes of molecules.

In a previous paper ${ }^{24}$ we argued that $\mathrm{BrHgNO}$ thermally dissociates faster than it could undergo other reactions. Given that $\mathrm{HOHgNO}$ and BrHgNO possess essentially the same $\mathrm{Hg}-\mathrm{N}$ bond energy, we conclude that the main fate of $\mathrm{HOHgNO}$ is dissociation. The same argument holds for individual molecules of $\mathrm{BrHgOO} \cdot$ and $\mathrm{HOHgOO} \cdot$. However, the abundance of $\mathrm{O}_{2}$ means that, at any given time, small fractions of $\mathrm{BrHg} \bullet$ and $\mathrm{HOHg} \bullet$ will exist as $\mathrm{BrHgOO} \bullet$ and $\mathrm{HOHgOO}^{-}$, respectively. Calculations at higher levels of theory are needed to obtain reliable values of $\mathrm{Hg}-\mathrm{O}_{2}$ bond energies in these radicals and to investigate the reactions of these compounds in the atmosphere.

Having dealt with the reactions of $\mathrm{HOHg} \bullet$ with abundant radicals, let us consider how $\mathrm{HOHg} \bullet$ might react with VOCs: by abstraction of hydrogen atoms or addition to $\mathrm{sp}^{2}$-hybridized carbon atoms. We previously reported that $\mathrm{BrHg} \bullet$ will not abstract hydrogen atoms from volatile organic compounds (VOCs). These reactions are thermodynamically disfavored due to the weakness of the $\mathrm{BrHg}-\mathrm{H}$ bond $\left(\mathrm{D}_{0}=73 \pm 3 \mathrm{kcal} / \mathrm{mole}\right){ }^{73}$ Here we report that the isodesmic reaction:

$$
\mathrm{HOHgH}+\mathrm{BrHg} \bullet \rightarrow \mathrm{HOHg} \bullet+\mathrm{BrHgH}
$$

possesses an enthalpy of reaction $($ at $0 \mathrm{~K})$ of $+3.5 \mathrm{kcal} / \mathrm{mole}$ at $\mathrm{CCSD}(\mathrm{T}) / \mathrm{PBE} 0 / \mathrm{AVTZ}$. This means that the $\mathrm{HOHg}-\mathrm{H}$ bond energy amounts to only $76 \pm 3 \mathrm{kcal} / \mathrm{mole}$, which is much weaker than $\mathrm{C}-\mathrm{H}$ and $\mathrm{O}-\mathrm{H}$ bonds in VOCs. Consequently, we do not expect HOHg $\bullet$ to abstract hydrogen atoms from VOCs. 
Our study ${ }^{73}$ of the $\mathrm{BrHg} \bullet+\mathrm{CH}_{2}=\mathrm{CH}_{2}$ reaction showed that, like $\mathrm{OH}+\mathrm{CH}_{2}=\mathrm{CH}_{2}$, this reaction proceeds by a barrierless formation of a van der Waals complex, which then passes over a transition state to form $\mathrm{BrHgCH}_{2} \mathrm{CH}_{2} \cdot$. Figure 5 depicts the potential energy profile for the analogous $\mathrm{HOHg} \bullet+$ ethylene system at PBE0/AVTZ. Like the analogous $\mathrm{BrHg}+$ ethylene reaction, this reaction is roughly thermoneutral. At the PBE0/AVTZ level of theory, we find that, as compared to the $\mathrm{BrHg} \bullet+\mathrm{CH}_{2}=\mathrm{CH}_{2}$ reaction, the transition state and reaction products in the $\mathrm{HOHg} \bullet+\mathrm{CH}_{2}=\mathrm{CH}_{2}$ system are both slightly higher in energy relative to reactants (by 1.4 and $3.2 \mathrm{kcal} / \mathrm{mole})$. As we showed, the weakness of the $\mathrm{BrHg}-\mathrm{CH}_{2} \mathrm{CH}_{2} \bullet$ bond means that this radical will dissociate before undergoing any bimolecular collisions. ${ }^{73}$ Given the higher barrier and lesser stability of the products in the $\mathrm{HOHg} \bullet+\mathrm{CH}_{2}=\mathrm{CH}_{2}$ reaction, we suggests that $\mathrm{HOHg} \bullet$ addition to alkenes will be very inefficient.

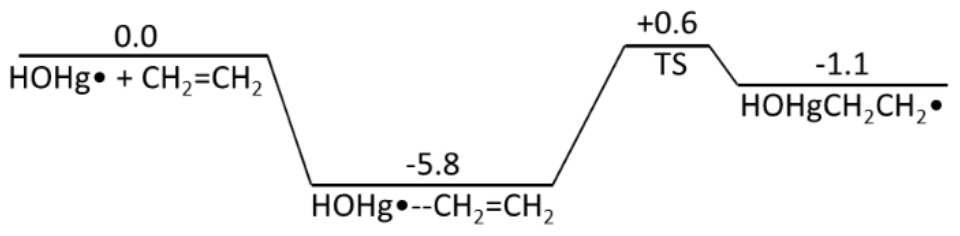

Figure 5. Potential energy profile for $\mathrm{HOHg}+\mathrm{CH}_{2}=\mathrm{CH}_{2}$ at PBE0/AVTZ.

Proposed Mechanism and Rate Constants for the $\mathrm{OH}$-Initiated oxidation of $\mathrm{Hg}(\mathbf{0})$. Based on the similarity of the $\mathrm{BrHg}-\mathrm{Y}$ and $\mathrm{HOHg}-\mathrm{Y}$ bond energies, their formation reactions will likely possess similar pressure- and temperature-dependent rate constants, $k([\mathrm{M}], T)$. For purposes of modeling, we suggest assuming that the values are identical. We fit the rate constants reported by Jiao and Dibble ${ }^{22}$ for $\mathrm{BrHg} \bullet+\mathrm{NO}_{2}$ and $\mathrm{BrHg} \bullet+\mathrm{HOO}$ to the Troe expression: ${ }^{74}$

$$
k([\mathrm{M}], T)=\left(\frac{k_{0}(T)[M]}{1+\frac{k_{0}\left(T^{T}\right)[M]}{k_{\varphi}\left(T^{T}\right)}}\right) F_{C}^{Y}
$$

where $F_{c}$ is assumed to be $0.6, k_{0}$ is the rate constant in the low-pressure limit, $k_{\infty}$ is the rate constant in the high-pressure limit, and $\gamma$ is defined by:

$$
\gamma=\left\{1+\left[\log _{10}\left(\frac{k_{0}(T)[M]}{k_{\infty}(T)}\right)\right]^{2}\right\}^{-1}
$$

The resulting values of $k_{0}(T)$ and $k_{\infty}(T)$ are listed in Table 5. Consistent with Horowitz et al., ${ }^{23}$ we assume the rate constant for $\mathrm{HOHg} \bullet+\bullet \mathrm{Y}$ takes on one value for $\mathrm{Y}=\bullet \mathrm{NO}_{2}$ and another value for all other $\bullet Y$.

It has been shown that $\mathrm{BrHg}-\mathrm{OX}$ bond energies vary rather little between $\mathrm{X}=\mathrm{Cl}, \mathrm{Br}$, and I; ${ }^{62,59}$ Guzman and Bozzelli showed this for HOHg-OX ${ }^{59}$ Consequently, we include $\mathrm{HOHg} \bullet$ reaction with $\mathrm{ClO}$ and $\mathrm{IO}$ in the mechanism in Table 5. In a previous paper, we demonstrated the 
existence of $\mathrm{BrHgXO}$ compounds $(\mathrm{X}=\mathrm{Cl}, \mathrm{Br}, \mathrm{I})$ that were $26-28 \mathrm{kcal} / \mathrm{mole}$ less stable than the corresponding $\mathrm{BrHgOX}$ species. ${ }^{62}$ So we confidently predict that the corresponding $\mathrm{HOHgXO}$ compounds exist and are similarly less stable than their $\mathrm{HOHgOX}$ counterparts.

Table 5. Mechanism and rate constants for the $\mathrm{OH}$-initiated oxidation of $\mathrm{Hg}(0)$. The reaction $\mathrm{OH}+\mathrm{Hg}+\mathrm{M} \leftrightarrows \mathrm{HOHg} \bullet+\mathrm{M}$ is assumed to be in the low-pressure limit.

\begin{tabular}{|l|c|}
\hline Reaction & Rate Constant $^{\mathrm{a}, \mathrm{b}}$ \\
\hline $\mathrm{OH}+\mathrm{Hg}+\mathrm{M} \rightarrow \mathrm{HOHg} \bullet+\mathrm{M}$ & $3.34 \times 10^{-33} \mathrm{e}^{-43 / \mathrm{T}}$ \\
\hline $\mathrm{HOHg} \bullet+\mathrm{M} \rightarrow \mathrm{OH}+\mathrm{Hg}+\mathrm{M}$ & $1.22 \times 10^{-9} \mathrm{e}^{+5720 / \mathrm{T}}$ \\
\hline $\mathrm{HOHg} \bullet+\mathrm{NO}_{2} \stackrel{\mathrm{M}}{\rightarrow}$ syn-HOHgONO & $\begin{array}{l}k_{0}(T)=7.1 \times 10^{-29}(\mathrm{~T} / 300)^{-4.5} \\
k_{\infty}(T)=1.2 \times 10^{-10}(\mathrm{~T} / 300)^{-1.9}\end{array}$ \\
\hline $\mathrm{HOHg} \cdot+\cdot \mathrm{Y} \stackrel{\mathrm{M}}{\rightarrow} \mathrm{HOHgY}$ & $k_{0}(T)=2.3 \times 10^{-29}(\mathrm{~T} / 300)^{-4.4}$ \\
$\cdot \mathrm{Y}=\left(\mathrm{HOO}, \mathrm{CH}_{3} \mathrm{OO}, \mathrm{ClO}, \mathrm{BrO}\right.$, etc. $)$ & $k_{\infty}(T)=6.9 \times 10^{-11}(\mathrm{~T} / 300)^{-2.4}$ \\
\hline
\end{tabular}

a) $k_{1}$ and both values of $k_{0}$ are in units of $\mathrm{cm}^{6}$ molecule $\mathrm{sec}^{-1} \cdot k_{-1}$ and $k_{\infty}$ are in units of $\mathrm{cm}^{3}$ molecule $\mathrm{sec}^{-1}$. b) $k_{0}(T)$ and $\mathrm{k}_{\infty}(T)$ are used in the Troe expression (Eqns. 16 and 17 in the text) to get $k([\mathrm{M}], T)$

Calvert and Lindberg ${ }^{12}$ buttressed their analysis of the experiment of Pal and Ariya ${ }^{10}$ with kinetic modeling. We carried out simulations based on their model, after updating the mercury chemistry and adding $\mathrm{OH}$ reaction with isopropylnitrite and multiple generations of reactions of the products. We find that the fate of $\mathrm{HOHg} \bullet$ under the experimental conditions of Pal and Ariya is almost entirely reaction with $\mathrm{NO}_{2}$ rather than dissociation. Analysis of the extent of formation of $\mathrm{NO}_{2}$ in the experiments of Sommar et al. ${ }^{8}$ reaches the same conclusion. Details of both analyses may be found in the Supporting Information.

Global Modeling of Oxidation of Gaseous Elemental Mercury We added the above mechanism of $\mathrm{OH}$-initiated oxidation of elemental mercury to the GEOS-Chem global chemistry and transport model ${ }^{75}$ to quantify its atmospheric efficiency and calculate its impact on global atmospheric $\mathrm{Hg}$. We simulated both $\mathrm{OH}$ - and $\mathrm{Br}$-initiated oxidation of elemental mercury using GEOS-Chem version 12.3.1. ${ }^{76}$ The GEOS-Chem model simulates concentrations of the relevant oxidant radical species $\left(\mathrm{OH}, \mathrm{Br}, \mathrm{Cl}, \mathrm{NO}_{2}, \mathrm{HO}_{2}, \mathrm{BrO}, \mathrm{ClO}\right.$, etc.), and we added mercury redox chemistry to this model's standard simulation. Organic peroxy radicals were not included as reactants with $\mathrm{BrHg} \bullet$ or $\mathrm{HOHg} \bullet$. We simulated $\mathrm{Hg}$ concentrations for the years 2013-2015 with $4^{\circ} \times 5^{\circ}$ horizontal resolution and 47 vertical levels, using emissions and land surface flux boundary conditions taken from Horowitz et al. ${ }^{23}$ As in that work, we coupled our atmospheric simulation to the MITgcm ocean $\mathrm{Hg}$ simulation. ${ }^{77}$ Horowitz et al. considered $\mathrm{Hg}(0)$ oxidation by $\mathrm{Br}$ and $\mathrm{Cl}$ atoms in the gas phase and by $\mathrm{OH}(\mathrm{aq}), \mathrm{O}_{3}(\mathrm{aq})$, and $\mathrm{HOCl}(\mathrm{aq})$ in cloudwater. They found that gas-phase oxidation by $\mathrm{Br}$ atoms accounted for $97 \%$ of the global formation of $\mathrm{Hg}$ (II).

Gas-phase $\mathrm{OH}$-initiated $\mathrm{Hg}$ oxidation was added as defined in Table 5. Other oxidation pathways were as in Horowitz et al. but the pressure and temperature dependence of the second stage of Br-initiated oxidation was changed to reflect the corresponding Troe expressions above. Following Saiz-Lopez et al., ${ }^{27}$ we used the photolysis cross sections of BrHgY species to 
calculate photolysis rate constants using the Fast-JX code implemented in GEOS-Chem. ${ }^{78,79}$ Photolysis of $\mathrm{BrHgY}$ is assumed to produce $\mathrm{BrHg} \bullet+\cdot \mathrm{Y}$ with the exception of $\mathrm{BrHgONO}$, which leads to $\mathrm{BrHgOH}$ via $\mathrm{BrHgO} \cdot{ }^{25}$ We assume that, for each $\mathrm{BrHgY}$ species, the analogous $\mathrm{HOHgY}$ species has the same photolysis properties. While the substitution of $\mathrm{OH}$ for $\mathrm{Br}$ should cause shifts in the absorption spectra and corresponding differences in photolysis lifetimes, this effect would have to be large to affect our overall conclusions. By treating the photo-reduction of $\mathrm{BrHgY}$ and $\mathrm{HOHgY}$ identically, our simulations isolate the impact of the $\mathrm{OH}$-initiated oxidation as described in this work.

Figure 6 shows the annually averaged fraction of $\mathrm{HOHg} \bullet$ (top) and $\mathrm{BrHg} \bullet$ (bottom) that goes on to form $\mathrm{Hg}(\mathrm{II})$ species. $\mathrm{OH}$-initiated oxidation is highly inefficient at ground level. At all surface locations in the simulation, less than $15 \%$ of $\mathrm{HOHg} \cdot$ goes on to form $\mathrm{Hg}$ (II) instead of decomposing to $\mathrm{Hg}(0)$. For most of the globe, this fraction is less than $5 \%$, but the Eastern United States, Europe, and Eastern China show elevated fractions due to the presence of higher quantities of second-stage oxidants such as $\mathrm{NO}_{2}$. In contrast to oxidation via $\mathrm{OH}, \mathrm{Br}$-initiated oxidation is more than $70 \%$ efficient at ground level for most of the Northern Hemisphere. Since thermal decomposition of $\mathrm{HOHg}$ competes with the second stage of oxidation, the efficiency of converting $\mathrm{HOHg} \bullet$ to $\mathrm{Hg}(\mathrm{II})$ increases with increasing altitude.
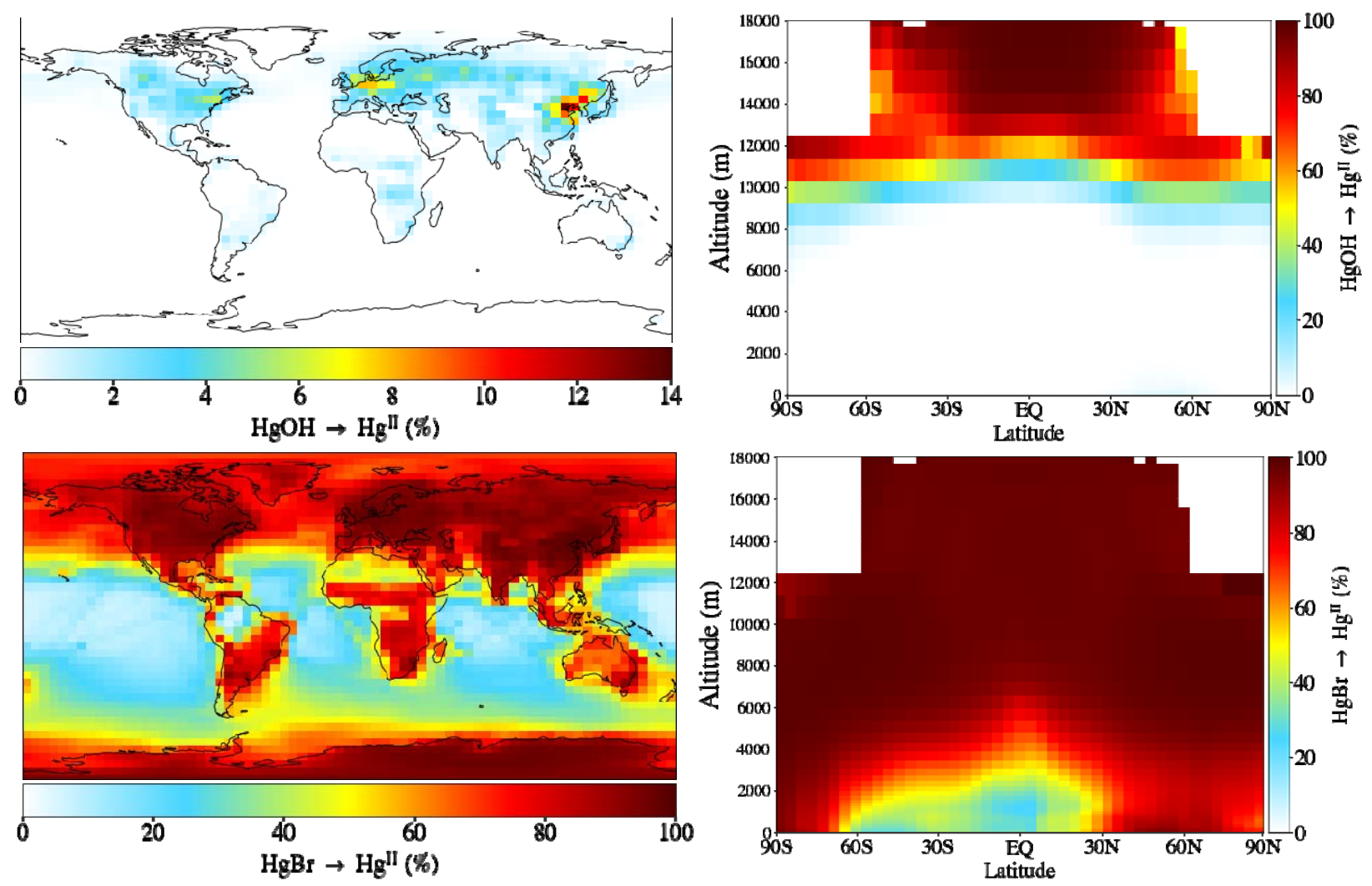

Figure 6. Annually averaged percent of $\mathrm{HOHg} \bullet$ (top) and $\mathrm{BrHg} \bullet$ (bottom) going on to form $\mathrm{Hg}$ (II) compounds. (Left) spatial variation at ground level for the entire globe. (Right) variation with altitude and latitude averaged over longitude. 
Because of the inefficiency of $\mathrm{OH}$-initiated oxidation, adding $\mathrm{OH}$-initiated oxidation to a model that already includes Br-initiated oxidation has a small effect on concentrations of total gaseous mercury (TGM, the sum of gas-phase $\mathrm{Hg}(0)$ and $\mathrm{Hg}(\mathrm{II})$ ). In highly polluted areas (North America, Europe and East Asia) concentrations of reactive gaseous mercury ( $\mathrm{Hg}(\mathrm{II})(\mathrm{g})$, aka RGM) increase by up to $5 \%$. Outside of these areas, $\mathrm{OH}$-initiated oxidation has effectively no insitu effect on RGM or TGM concentrations. However, the addition of $\mathrm{OH}$-initiated oxidation near sources of $\mathrm{Hg}$ emissions decreases the atmospheric lifetime of these emissions, and decreases global TGM mass by $2 \%$. Figure 7 shows the fraction of total $\mathrm{Hg}$ (II) formation originating from $\mathrm{Hg}+\mathrm{OH}$. In the most polluted regions, it can reach up to $83 \%$, but is less than $1 \%$ for the majority of the globe at ground level. Globally, $\mathrm{Hg}+\mathrm{OH}$ contributes $0.5 \%$ of $\mathrm{Hg}(\mathrm{II})$ formation.
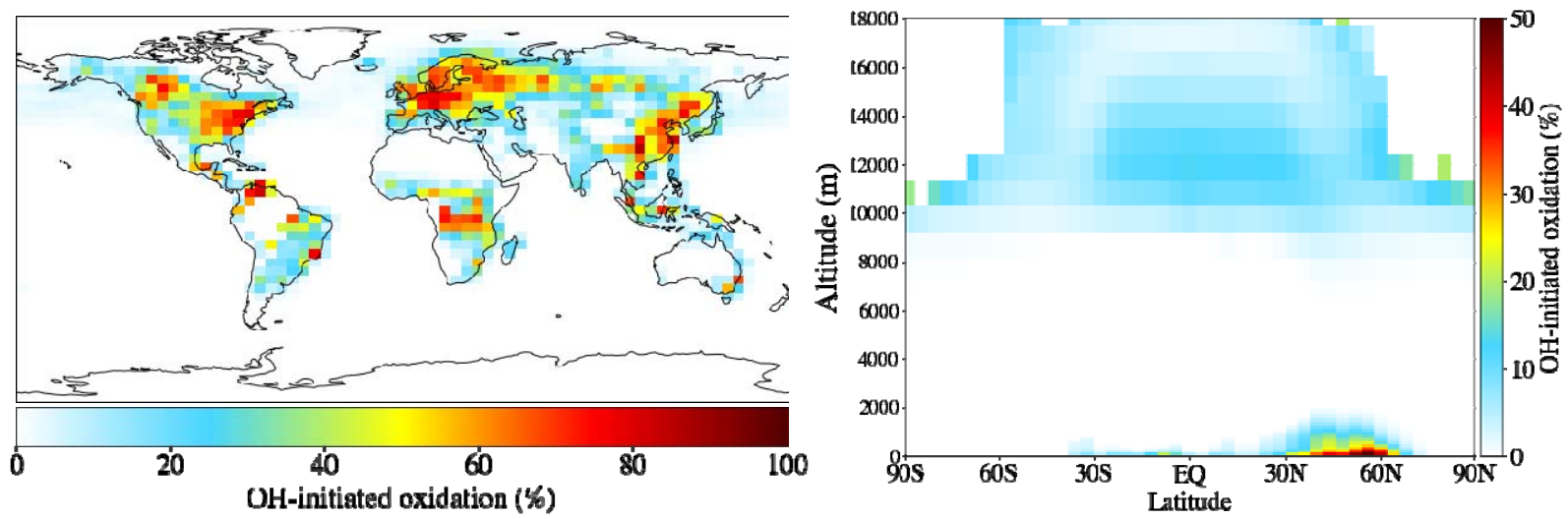

Figure 7. Annually averaged percent of total oxidation initiated by OH. (Left) spatial variation at ground level for the entire globe. (Right) variation with altitude and latitude averaged over longitude.

Recently, Saiz-Lopez et al. ${ }^{26}$ suggested that photolysis of HOHg• and BrHg• could be an important atmospheric reduction process, and that photolysis occurs somewhat more rapidly for $\mathrm{BrHg} \bullet$ than $\mathrm{HOHg} \cdot$. Inclusion of this effect would not make $\mathrm{OH}$ important for global oxidation of GEM.

\section{CONCLUSIONS AND FURTHER WORK}

We have presented a mechanism and rate constants for the two-step oxidation of $\operatorname{Hg}(0)$ initiated by $\mathrm{OH}$ radical in the gaseous atmosphere. We implemented these results into the GEOSChem global atmospheric $\mathrm{Hg}$ model. The resulting simulations predict that the main pathway for $\mathrm{Hg}(0)$ oxidation to $\mathrm{Hg}(\mathrm{II})$ occurs through the initial $\mathrm{Hg}+\mathrm{Br}$ reaction. We find that the $\mathrm{Hg}+\mathrm{OH}$ pathway contributes $<1 \%$ of the conversion of $\operatorname{Hg}(0)$ to $\operatorname{Hg}(\mathrm{II})$, globally, but up to $83 \%$ in polluted regions.

Experimental investigation of $k_{1}([\mathrm{M}], T)$ using direct monitoring of $\mathrm{OH}$ radical by LIF only led to an upper limit to $k_{1}(298) .{ }^{9}$ Under those experimental conditions, the lifetime for loss of $\mathrm{OH}$ 
by processes other than reaction with $\mathrm{Hg}(0)$ was about $5 \mathrm{~ms}$. Our results indicate that $\mathrm{HOHg} \bullet$ possesses a lifetime of $7 \mathrm{~ms}$ at $298 \mathrm{~K}$ and 1 atm of air. Consequently, we suggest that the fast regeneration of $\mathrm{OH}$ from dissociation of $\mathrm{HOHg} \bullet$ does not present an insuperable obstacle to use of LIF to measure $k_{1}$.

Experimental measurements of $k-1([\mathrm{M}], T)$ would improve the reliability of our model of $\mathrm{HOHg} \bullet$ formation and dissociation. Note that Saiz-Lopez et al. ${ }^{26}$ reported that $\mathrm{HOHg} \bullet$ will be photolyzed with a global lifetime of $\sim 100$ seconds, but experiments are needed to verify their computed photo-absorption cross-sections. Experimentally determining either $k-1([\mathrm{M}], T)$ or these photo-absorption cross-section will be a challenge, since, to date, $\mathrm{HOHg} \bullet$ has only been detected in a single laboratory study, and only in aqueous solution. ${ }^{80}$

Except for the value of the bimolecular rate constant, $k_{1}(T, 1 \mathrm{~atm})$, over the range $283 \mathrm{~K} \leq T$ $\leq 353 \mathrm{~K}$, our entire mechanism is based on computational chemistry and chemical insight. In particular, the rate constants for $\mathrm{BrHg} \bullet$ reaction with $\mathrm{NO}_{2}$ and $\mathrm{HOO} \bullet$ used for the $\mathrm{HOHg} \bullet+\cdot \mathrm{Y}$ reactions are, themselves, the result of calculations that have yet to be verified by experiment. Validation or improvement of the $\mathrm{HOHg} \bullet+\cdot \mathrm{Y}$ rate constants is a high-priority item for improving the reliability of our mechanism.

Previously, Saiz-Lopez et al. reported relativistic CASPT2 calculations indicating that photolysis of BrHgY compounds occurs very rapidly in the atmosphere, ${ }^{27}$ and Lam et al. affirmed this for BrHgONO using non-relativistic EOM-CCSD calculations. ${ }^{25}$ No laboratory experimental data has been reported for any $\mathrm{BrHgY}$ or $\mathrm{HOHgY}$ compound, and the spectra of $\mathrm{HOHgY}$ compounds has not been computed. These compounds are important targets for future studies, since atmospheric modelers need to know their spectra, photolysis quantum yields, and whether their photolysis leads to photo-reduction.

\section{ASSOCIATED CONTENT}

\section{Supporting Information}

The Supporting Information is available free of charge on the ACS Publications website at DOI: _. Absolute energies of all species at all levels of theory along with zero-point energies, structural data, rotational constants, and vibrational frequencies; values of the T1 diagnostic; thermochemical data; kinetic analyses of previous experiments; Figures showing additional model results (PDF); kinetic model for analysis of experiment (Excel).

\section{ACKNOWLEDGEMENTS}

The work at SUNY-ESF was partially supported by the National Science Foundation under award 1609848. Some computations were carried out using resources of the Extreme Science and Engineering Discovery Environment (XSEDE), which is supported by National Science Foundation Grant Number ACI-1053575; specifically, we used Bridges at the Pittsburgh Supercomputing Center (PSC) and Comet at the San Diego Supercomputer Center (SDSC). We 
also thank Huiting Mao for helpful discussions and Khoa T. Lam for advice on calculations. The work at Harvard was supported by the US National Science Foundation Atmospheric Chemistry Program under award AGS-1643217.

\section{TOC Graphic}

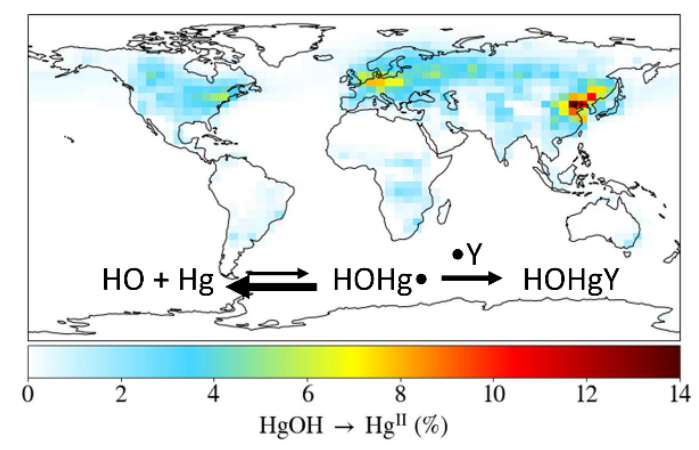




\section{REFERENCES}

(1) Driscoll, C. T.; Mason, R. P.; Chan, H. M.; Jacob, D. J.; Pirrone, N. Mercury as a Global Pollutant: Sources, Pathways, and Effects. 2013, 47, 4967-4983.

(2) Minimata Convention on Mercury. 2013.http:// www.mercuryconvention.org

(3) Zhang, L.; Wang, S.; Wu, Q.; Wang, F.; Lin, C.-J.; Zhang, L.; Hui, M.; Yang, M.; Su, H.; Hao, J. Mercury Transformation and Speciation in Flue Gases from Anthropogenic Emission Sources: A Critical Review. Atmos. Chem. Phys. 2016, 16 (4), 2417-2433.

(4) Schroeder, W. H.; Munthe, J. Atmospheric Mercury-An Overview. Atmos. Environ. 1998, 32 (5), 809-822.

(5) Lin, C. J.; Pongprueksa, P.; Bullock, R. O.; Lindberg, S. E.; Pehkonen, S. O.; Jang, C.; Braverman, T.; Ho, T. C. Scientific Uncertainties in Atmospheric Mercury Models II: Sensitivity Analysis in the CONUS Domain. Atmos. Environ. 2007, 41 (31), 6544-6560.

(6) Gustin, M. S.; Amos, H. M.; Huang, J.; Miller, M. B.; Heidecorn, K. Measuring and Modeling Mercury in the Atmosphere: A Critical Review. Atmos. Chem. Phys. 2015, 15 (10), 5697-5713.

(7) Gencarelli, C. N.; Bieser, J.; Carbone, F.; De Simone, F.; Hedgecock, I. M.; Matthias, V.; Travnikov, O.; Yang, X.; Pirrone, N. Sensitivity Model Study of Regional Mercury Dispersion in the Atmosphere. Atmos. Chem. Phys. 2017, 17 (1), 627-643.

(8) Sommar, J.; Gårdfeldt, K.; Strömberg, D.; Feng, X. A Kinetic Study of the Gas-Phase Reaction between the Hydroxyl Radical and Atomic Mercury. Atmos. Environ. 2001, 35 (17), 3049-3054.

(9) Bauer, D.; D’Ottone, L.; Campuzano-Jost, P.; Hynes, A. . Gas Phase Elemental Mercury: A Comparison of LIF Detection Techniques and Study of the Kinetics of Reaction with the Hydroxyl Radical. J. Photochem. Photobiol. A Chem. 2003, 157 (2-3), 247-256.

(10) Pal, B.; Ariya, P. A. Gas-Phase HO-Initiated Reactions of Elemental Mercury: Kinetics, Product Studies, and Atmospheric Implications. Environ. Sci. Technol. 2004, 38 (21), 5555-5566.

(11) Goodsite, M. E. Plane, J. M. C.; Skov, H. A Theoretical Study of the Oxidation of $\operatorname{Hg}^{0}$ to $\mathrm{HgBr}_{2}$ in the Troposphere. Environ. Sci. Technol. 2004, 38 (6), 1772-1776.

(12) Calvert, J. G.; Lindberg, S. E. Mechanisms of Mercury Removal by $\mathrm{O}_{3}$ and $\mathrm{OH}$ in the Atmosphere. Atmos. Environ. 2005, 39 (18), 3355-3367.

(13) Travnikov, O.; Angot, H.; Artaxo, P.; Bencardino, M.; Bieser, J.; D’Amore, F.; Dastoor, A.; De Simone, F.; Diéguez, M. D. C.; Dommergue, A.; et al. Multi-Model Study of Mercury Dispersion in the Atmosphere: Atmospheric Processes and Model Evaluation. Atmos. Chem. Phys. 2017, 17 (8), 5271-5295.

(14) Bullock, O. R.; Brehme, K. A. Atmospheric Mercury Simulation Using the CMAQ Model: Formulation Description and Analysis of Wet Deposition Results. Atmos. Environ. 2002, 36 (13), 2135-2146. 
(15) Jung, G.; Hedgecock, I. M.; Pirrone, N. ECHMERIT V1.0 - a New Global Fully Coupled Mercury-Chemistry and Transport Model. Geosci. Model Dev. 2009, 2 (2), 175-195.

(16) Shepler, B. C.; Peterson, K. A. Mercury Monoxide: A Systematic Investigation of Its Ground Electronic State. J. Phys. Chem. A 2003, 107 (11), 1783-1787.

(17) Filatov, M.; Cremer, D. Revision of the Dissociation Energies of Mercury ChalcogenidesUnusual Types of Mercury Bonding. Chemphyschem 2004, 5 (10), 1547-1557.

(18) Tossell, J. A. Calculation of the Energetics for the Oligomerization of Gas Phase $\mathrm{HgO}$ and $\mathrm{HgS}$ and for the Solvolysis of Crystalline HgO and HgS. J. Phys. Chem. A 2006, 110 (7), 2571-2578.

(19) Peterson, K. A.; Shepler, B. C.; Singleton, J. M. The Group 12 Metal Chalcogenides: An Accurate Multireference Configuration Interaction and Coupled Cluster Study. Mol. Phys. 2007, 105 (9), 1139-1155.

(20) Cremer, D.; Kraka, E.; Filatov, M. Bonding in Mercury Molecules Described by the Normalized Elimination of the Small Component and Coupled Cluster Theory. ChemPhysChem 2008, 9 (17), 2510-2521.

(21) Dibble, T. S.; Zelie, M. J.; Mao, H. Thermodynamics of Reactions of ClHg and BrHg Radicals with Atmospherically Abundant Free Radicals. Atmos. Chem. Phys. 2012, 12 (21), 10271-10279.

(22) Jiao, Y.; Dibble, T. S. First Kinetic Study of the Atmospherically Important Reactions $\mathrm{BrHg}+\mathrm{NO}_{2}$ and BrHg + HOO. Phys. Chem. Chem. Phys. 2017, 19 (3), 1826-1838.

(23) Horowitz, H. M.; Jacob, D. J.; Zhang, Y.; Dibble, T. S.; Slemr, F.; Amos, H. M.; Schmidt, J. A.; Corbitt, E. S.; Marais, E. A.; Sunderland, E. M. A New Mechanism for Atmospheric Mercury Redox Chemistry: Implications for the Global Mercury Budget. Atmos. Chem. Phys. 2017, 17, 6353-6371.

(24) Jiao, Y.; Dibble, T. S. Quality Structures, Vibrational Frequencies, and Thermochemistry of the Products of Reaction of $\mathrm{BrHg}$ with $\mathrm{NO}_{2}, \mathrm{HO}_{2}, \mathrm{ClO}, \mathrm{BrO}$, and IO. J. Phys. Chem. A 2015, 119 (42), 10502-10510.

(25) Lam, K. T.; Wilhelmsen, C. J.; Schwid, A. C.; Jiao, Y.; Dibble, T. S. Computational Study on the Photolysis of $\mathrm{BrHgONO}$ and the Reactions of $\mathrm{BrHgO} \bullet$ with $\mathrm{CH}_{4}, \mathrm{C}_{2} \mathrm{H}_{6}, \mathrm{NO}$, and $\mathrm{NO}_{2}$ : Implications for Formation of $\mathrm{Hg}$ (II) Compounds in the Atmosphere. J. Phys. Chem. A 2019, 123 (8), 1637-1647.

(26) Saiz-Lopez, A.; Ulises Acuña, A.; Trabelsi, T.; Carmona-García, J.; Z. Dávalos, J.; Rivero, D.; A. Cuevas, C.; E. Kinnison, D.; P. Sitkiewicz, S.; Roca-Sanjuán, D.; et al. Gas-Phase Photolysis of $\mathrm{Hg}(\mathrm{I})$ Radical Species: A New Atmospheric Mercury Reduction Process. $J$. Am. Chem. Soc. 2019, 141 (22), 8698-8702.

(27) Saiz-Lopez, A.; Sitkiewicz, S. P.; Roca-Sanjuán, D.; Oliva-Enrich, J. M.; Dávalos, J. Z.; Notario, R.; Jiskra, M.; Xu, Y.; Wang, F.; Thackray, C. P.; et al. Photoreduction of Gaseous Oxidized Mercury Changes Global Atmospheric Mercury Speciation, Transport and Deposition. Nat. Commun. 2018, 9 (1), 4796. 
(28) Sun, G.; Sommar, J.; Feng, X.; Lin, C.-J.; Ge, M.; Wang, W.; Yin, R.; Fu, X.; Shang, L. Mass-Dependent and -Independent Fractionation of Mercury Isotope during Gas-Phase Oxidation of Elemental Mercury Vapor by Atomic $\mathrm{Cl}$ and Br. Environ. Sci. Technol. 2016, 50 (17), 9232-9241.

(29) Dibble, T. S.; Zelie, M. J.; Mao, H. Thermodynamics of Reactions of ClHg and BrHg Radicals with Atmospherically Abundant Free Radicals. Atmos. Chem. Phys. 2012, 12 (21), 10271-10279.

(30) Frisch, M. J.; Trucks, G. W.; Schlegel, H. B.; Scuseria, G. E.; Robb, M. A.; Cheeseman, J. R.; Scalmani, G.; Barone, V.; Petersson, G. A.; Nakatsuji, H.; et al. Gaussian 09, Revision D.01. Wallingford CT 2016.

(31) Frisch, M. J.; Trucks, G. W.; Schlegel, H. B.; Scuseria, G. E.; Robb, M. A.; Cheeseman, J. R.; Scalmani, G.; Barone, V.; Petersson, G. A.; Nakatsuji, H.; Li, X.; Caricato, M.; Marenich, A. V.; Bloino, J.; Janesko, B. G.; Gomperts, R.; Mennucci, B.; Hratch, D. J. Gaussian 16, Rev. A. Gaussian, Inc.: Wallingford CT 2016.

(32) Kendall, R. A.; Dunning, T. H.; Harrison, R. J. Electron Affinities of the First-row Atoms Revisited. Systematic Basis Sets and Wave Functions. J. Chem. Phys. 1992, 96 (9), 67966806.

(33) Peterson, K. A.; Figgen, D.; Goll, E.; Stoll, H.; Dolg, M. Systematically Convergent Basis Sets with Relativistic Pseudopotentials. II. Small-Core Pseudopotentials and Correlation Consistent Basis Sets for the Post-d Group 16-18 Elements. J. Chem. Phys. 2003, 119 (21), 11113.

(34) Figgen, D.; Rauhut, G.; Dolg, M.; Stoll, H. Energy-Consistent Pseudopotentials for Group 11 and 12 Atoms: Adjustment to Multi-Configuration Dirac-Hartree-Fock Data. Chem. Phys. 2005, 311 (1-2), 227-244.

(35) Peterson, K. A.; Shepler, B. C.; Figgen, D.; Stoll, H. On the Spectroscopic and Thermochemical Properties of ClO, BrO, IO, and Their Anions. J. Phys. Chem. A 2006, 110 (51), 13877-13883.

(36) Peterson, K. A.; Puzzarini, C. Systematically Convergent Basis Sets for Transition Metals. II. Pseudopotential-Based Correlation Consistent Basis Sets for the Group $11(\mathrm{Cu}, \mathrm{Ag}, \mathrm{Au})$ and 12 (Zn, Cd, Hg) Elements. Theor. Chem. Acc. 2005, 114 (4-5), 283-296.

(37) Tajti, A.; Szalay, P. G.; Császár, A. G.; Kállay, M.; Gauss, J.; Valeev, E. F.; Flowers, B. A.; Vázquez, J.; Stanton, J. F. HEAT: High Accuracy Extrapolated Ab Initio Thermochemistry. J. Chem. Phys. 2004, 121 (23), 11599-11613.

(38) Bomble, Y. J.; Vázquez, J.; Kállay, M.; Michauk, C.; Szalay, P. G.; Császár, A. G.; Gauss, J.; Stanton, J. F. High-Accuracy Extrapolated Ab Initio Thermochemistry. II. Minor Improvements to the Protocol and a Vital Simplification. J. Chem. Phys. 2006, 125 (6), 064108 .

(39) Stanton, J. F.; Gauss, J.; Harding, M. E.; Szalay, P. G. CFOUR, Coupled-Cluster Techniques for Computational Chemistry. http://www.cfour.de

(40) Kállay, M.; Rolik, Z.; Csontos, J.; Nagy, P.; Samu, G.; Mester, D.; Ladjánszki, I.; Szegedy, 
L.; Ladóczki, B.; Petrov, K.; et al. MRCC, a Quantum Chemical Program Suite.

(41) Aquilante, F.; Autschbach, J.; Carlson, R. K.; Chibotaru, L. F.; Delcey, M. G.; De Vico, L.; Fdez Galván, I.; Ferré, N.; Frutos, L. M.; Gagliardi, L.; et al. Molcas 8: New Capabilities for Multiconfigurational Quantum Chemical Calculations across the Periodic Table. $J$. Comput. Chem. 2016, 37 (5), 506-541.

(42) Cheng, L.; Gauss, J. Analytic Energy Gradients for the Spin-Free Exact Two-Component Theory Using an Exact Block Diagonalization for the One-Electron Dirac Hamiltonian. $J$. Chem. Phys. 2011, 135 (8), 084114.

(43) Peterson, K. A.; Dunning, T. H. Accurate Correlation Consistent Basis Sets for Molecular Core-Valence Correlation Effects: The Second Row Atoms Al-Ar, and the First Row Atoms B-Ne Revisited. J. Chem. Phys. 2002, 117 (23), 10548-10560.

(44) Peterson, K. A.; Woon, D. E.; Dunning, T. H. Benchmark Calculations with Correlated Molecular Wave Functions. IV. The Classical Barrier Height of the $\mathrm{H}+\mathrm{H} 2 \rightarrow \mathrm{H}_{2}+\mathrm{H}$ Reaction. J. Chem. Phys. 1994, 100 (10), 7410-7415.

(45) Feller, D.; Peterson, K. A. Re-Examination of Atomization Energies for the Gaussian-2 Set of Molecules. J. Chem. Phys. 1999, 110 (17), 8384-8396.

(46) Noga, J.; Bartlett, R. J. The Full CCSDT Model for Molecular Electronic Structure. J. Chem. Phys. 1987, 86 (12), 7041.

(47) Scuseria, G. E.; Schaefer, H. F. A New Implementation of the Full CCSDT Model for Molecular Electronic Structure. Chem. Phys. Lett. 1988, 152 (4-5), 382-386.

(48) Bomble, Y. J.; Stanton, J. F.; Kállay, M.; Gauss, J. Coupled-Cluster Methods Including Noniterative Corrections for Quadruple Excitations. J. Chem. Phys. 2005, 123 (5), 054101.

(49) Kállay, M.; Gauss, J. Approximate Treatment of Higher Excitations in Coupled-Cluster Theory. J. Chem. Phys. 2005, 123 (21), 214105.

(50) Malmqvist, P. Å.; Roos, B. O. The CASSCF State Interaction Method. Chem. Phys. Lett. 1989, 155 (2), 189-194.

(51) Malmqvist, P. Å.; Roos, B. O.; Schimmelpfennig, B. The Restricted Active Space (RAS) State Interaction Approach with Spin-Orbit Coupling. Chem. Phys. Lett. 2002, 357 (3-4), 230-240.

(52) Roos, B. O.; Malmqvist, P. A. Relativistic Quantum Chemistry: The Multiconfigurational Approach. Phys. Chem. Chem. Phys. 2004, 6 (11), 2919-2927.

(53) Ghigo, G.; Roos, B. O.; Malmqvist, P.-Å. A Modified Definition of the Zeroth-Order Hamiltonian in Multiconfigurational Perturbation Theory (CASPT2). Chem. Phys. Lett. 2004, 396 (1-3), 142-149.

(54) Heß, B. A.; Marian, C. M.; Wahlgren, U.; Gropen, O. A Mean-Field Spin-Orbit Method Applicable to Correlated Wavefunctions. Chem. Phys. Lett. 1996, 251 (5-6), 365-371.

(55) Roos, B. O.; Lindh, R.; Malmqvist, P. Å.; Veryazov, V.; Widmark, P. O. New Relativistic ANO Basis Sets for Transition Metal Atoms. J. Phys. Chem. A 2005, 109 (29), 6575-6579. 
(56) Roos, B. O.; Lindh, R.; Malmqvist, P. Å.; Veryazov, V.; Widmark, P. O. Main Group Atoms and Dimers Studied with a New Relativistic ANO Basis Set. J. Phys. Chem. A 2004, 108 (15), 2851-2858.

(57) Brown, J. M.; Kerr, C. M. L.; Wayne, F. D.; Evenson, K. M.; Radford, H. E. The FarInfrared Laser Magnetic Resonance Spectrum of the OH Radical. J. Mol. Spectrosc. 1981, 86 (2), 544-554.

(58) Ezarfi, N.; Touimi Benjelloun, A.; Sabor, S.; Benzakour, M.; Mcharfi, M. Theoretical Investigations of Structural, Thermal Properties and Stability of the Group 12 Metal $\mathrm{M}(\mathrm{XH})$ Isomers in Atmosphere: $\mathrm{M}=(\mathrm{Zn}, \mathrm{Cd}, \mathrm{Hg})$ and $\mathrm{XH}=(\mathrm{OH}, \mathrm{SH})$. Theor. Chem. Acc. 2019, 138 (9), 109.

(59) Guzman, F. J.; Bozzelli, J. Thermodynamics of $\mathrm{OHgX}, \mathrm{XHgOH}, \mathrm{XHgOCl}, \mathrm{XHgOBr}$, and $\mathrm{HOHgY}$ Gaseous Oxidized Mercury Molecules from Isodesmic, Isogyric, and Atomization Work Reactions ( $\mathrm{X}=$ Halogen, $\mathrm{Y}=\mathrm{OH}, \mathrm{OCl}, \mathrm{OBr})$. J. Phys. Chem. A 2019, 123 (20), 4452-4464.

(60) Lee, T. J.; Taylor, P. R. A Diagnostic for Determining the Quality of Single-Reference Electron Correlation Methods. Int. J. Quantum Chem. 2009, 36 (S23), 199-207.

(61) Harding, M. E.; Vázquez, J.; Ruscic, B.; Wilson, A. K.; Gauss, J.; Stanton, J. F. HighAccuracy Extrapolated Ab Initio Thermochemistry. III. Additional Improvements and Overview. J. Chem. Phys. 2008, 128 (11), 114111.

(62) Jiao, Y.; Dibble, T. S. Structures, Vibrational Frequencies, and Bond Energies of the $\mathrm{BrHgOX}$ and $\mathrm{BrHgXO}$ Species Formed in Atmospheric Mercury Depletion Events. $J$. Phys. Chem. A 2017, 121 (41).

(63) Tossell, J. A. Calculation of the Energetics for Oxidation of Gas-Phase Elemental Hg by $\mathrm{Br}$ and BrO. J. Phys. Chem. A 2003, 107 (39), 7804-7808.

(64) Chase, M. W., J. NIST-JANAF Thermochemical Tables, 4th Ed., Journal of Physical and Chemical Reference Data Monographs 9; 1998.

(65) Bakk, I. P.; Benkö, N.; Nyulászi, L. The Effect of Contaminants on the Mercury Consumption of Fluorescent Lamps. J. Phys. D. Appl. Phys. 2009, 42 (9), 095501.

(66) Balabanov, N. B.; Peterson, K. A. Mercury and Reactive Halogens: The Thermochemistry of $\mathrm{Hg}+\left\{\mathrm{Cl}_{2}, \mathrm{Br} 2, \mathrm{BrCl}, \mathrm{ClO}\right.$, and $\left.\mathrm{BrO}\right\}$. J. Phys. Chem. A 2003, 107 (38), 7465-7470.

(67) Donohoue, D. L.; Bauer, D.; Hynes, A. J. Temperature and Pressure Dependent Rate Coefficients for the Reaction of $\mathrm{Hg}$ with $\mathrm{Cl}$ and the Reaction of $\mathrm{Cl}$ with $\mathrm{Cl}$ : A Pulsed Laser Photolysis-Pulsed Laser Induced Fluorescence Study. J. Phys. Chem. A 2005, 109, 7732-7741.

(68) Donohoue, D. L.; Bauer, D.; Cossairt, B.; Hynes, A. J. Temperature and Pressure Dependent Rate Coefficients for the Reaction of $\mathrm{Hg}$ with $\mathrm{Br}$ and the Reaction of $\mathrm{Br}$ with Br: A Pulsed Laser Photolysis-Pulsed Laser Induced Fluorescence Study. J. Phys. Chem. A 2006, 110, 6623-6632.

(69) Barker, J. R. Multiple-Well, Multiple-Path Unimolecular Reaction Systems. I. MultiWell 
Computer Program Suite. Int. J. Chem. Kinet. 2001, 33 (4), 232-245.

(70) Barker, J. R. Energy Transfer in Master Equation Simulations: A New Approach. Int. J. Chem. Kinet. 2009, 41 (12), 748-763.

(71) Barker, J. R.; Nguyen, T. L.; Stanton, J. F.; Aieta, C.; Ceotto, M.; Gabas, F.; Kumar, T. J. D.; Li, C. G. L.; Lohr, L. L.; Maranzana, A.; et al. MultiWell-2019 Software Suite; J. R. Barker, University of Michigan, Ann Arbor, Michigan, USA, 2019 H.

(72) R. Glowacki, D.; Liang, C.-H.; Morley, C.; J. Pilling, M.; H. Robertson, S. MESMER: An Open-Source Master Equation Solver for Multi-Energy Well Reactions. J. Phys. Chem. A 2012, 116 (38), 9545-9560.

(73) Dibble, T. S.; Schwid, A. C. Thermodynamics Limits the Reactivity of BrHg• Radical with Volatile Organic Compounds. Chem. Phys. Lett. 2016, 659, $289-294$.

(74) Troe, J. Predictive Possibilities of Unimolecular Rate Theory. J. Phys. Chem. 1979, 83 (1), $114-126$.

(75) Bey, I.; Jacob, D. J.; Yantosca, R. M.; Logan, J. A.; Field, B. D.; Fiore, A. M.; Li, Q.; Liu, H. Y.; Mickley, L. J.; Schultz, M. G. Global Modeling of Tropospheric Chemistry with Assimilated Meteorology: Model Description and Evaluation. J. Geophys. Res. Atmos. 2001, 106 (D19), 23073-23095.

(76) International GEOS-Chem User Community. GEOS-Chem 12.3.1. 2019. http://dx.doi.org/10.5281/zenodo.2633278

(77) Zhang, Y.; Jacob, D. J.; Dutkiewicz, S.; Amos, H. M.; Long, M. S.; Sunderland, E. M. Biogeochemical Drivers of the Fate of Riverine Mercury Discharged to the Global and Arctic Oceans. Global Biogeochem. Cycles 2015, 29 (6), 854-864.

(78) Bian, H.; Prather, M. J. Fast-J2: Accurate Simulation of Stratospheric Photolysis in Global Chemical Models. J. Atmos. Chem. 2002, 41 (3), 281-296.

(79) Mao, J.; Fan, S.; Jacob, D. J.; Travis, K. R. Radical Loss in the Atmosphere from Cu-Fe Redox Coupling in Aerosols. Atmos. Chem. Phys. 2013, 13 (2), 509-519.

(80) Fujita, S.; Horii, H.; Mori, T.; Taniguchi, S. Pulse Radiolysis of Mercuric Oxide in Neutral Aqueous Solutions. J. Phys. Chem. 1975, 79 (10), 960-964. 